DOI: $10.5216 /$ cab.v13i4.18029

\title{
AVALIAÇÃO DAS CARACTERISTICAS SEMINAIS DE VARRÕES MANTIDOS EM CENTRAIS DE INSEMINAÇÃO ARTIFICIAL COM AMBIENTE CLIMATIZADO E NÃO CLIMATIZADO DURANTE 12 MESES
}

\author{
GUSTAVO EDUARdo FRENEAU ${ }^{1}$, JOAO DANILO JESUS FERREIRA ${ }^{2}$, JURIJ SOBESTIANSKY ${ }^{1}$
}

${ }^{1}$ Professores Doutores da Universidade Federal de Goiás, Goiânia, GO, Brasil. gfreneau @ gmail.com

${ }^{2}$ Mestre em Biologia pela Universidade Federal de Goiás, Goiânia, GO, Brasil.

\section{RESUMO}

Objetivou-se com o presente estudo avaliar e monitorar a qualidade dos ejaculados de suínos durante 12 meses, em duas granjas (climatizada e não climatizada). Cinco animais foram mantidos em cada uma das granjas - com ambiente climatizado (G1) e ambiente não climatizado (G2) - e submetidos a coletas e avaliação dos ejaculados a cada 15 dias. Foram estabelecidos escores de motilidade progressiva, concentração e morfologia espermática (MOT, CONC e MORF, respectivamente), que somados compõem a capacidade andrológica por pontos para suínos (CAP), com amplitude de 1 a 100 pontos e cinco classes: A-E. Houve diferença em várias características seminais ao longo do ano dentro e entre as granjas em épocas de temperatura e índice de temperatura e umidade mais elevados. Observaram-se diferenças entre granjas em relação à MOT $(13,1 \pm 4,0$ e $12,0 \pm 3,6)$, à MORF $(35,5 \pm 11,4$ e $27,6 \pm 11,6)$, à CONC $(21,6 \pm 16,8$ e $13,4 \pm 10,6)$ e ao CAP $(70,2 \pm 21,5$ e $53,0 \pm 18,8)$ e as frequências de animais dentro das classes do CAP foram de $\mathrm{A}=17,92 \%$ e $0,83 \%, \mathrm{~B}=13,75 \%$ e $21,25 \%, \mathrm{C}=16,67 \%$ e $21,67 \%, \mathrm{D}=1,25 \%$ e $4,17 \%, \mathrm{E}=0,42 \%$ e $2,08 \%$, para $\mathrm{G} 1$ e $\mathrm{G} 2$, respectivamente. Os ejaculados apresentaram menor qualidade nos meses de maior temperatura ambiente e índice de temperatura e umidade. Houve diferenças entre e dentro das granjas. Observaram-se correlações entre o CAP com as características seminais e a produção de doses inseminantes com diferentes critérios de qualidade. A avaliação dos aspectos morfológicos de ejaculados de suínos apresentaram variações, com menor qualidade nos meses de maior temperatura e índice de temperatura e umidade. A granja climatizada apresentou melhores parâmetros seminais ao longo do ano. As médias do CAP e as frequências de ejaculados dentro das classes do CAP refletiram as variações sazonais dos ejaculados. Da mesma forma, as doses inseminantes apresentaram variações em número quando se consideraram as características de qualidade dos ejaculados.

PALAVRAS-CHAVE: avaliação andrológica; morfologia espermática; sêmen; suíno; temperatura; umidade.

\section{SEMINAL CHARACTERISTICS OF BOARS IN ARTIFICIAL INSEMINATION FARMS IN AIR-CONDITIONED AND NON-AIR-CONDITIONED ENVIRONMENT DURING 12 MONTHS}

\section{ABSTRACT}

The purpose of this study was to evaluate boars' ejaculate during 12 months. Five boars were located in each artificial insemination farm with air-conditioned $(\mathrm{G} 1)$ and non- air-conditioned (G2) environment, and submitted to ejaculate examination every two weeks. Scores for sperm progressive motility, concentration and morphology (MOT, CONC and MORPH, respectively) were established. These scores were summed up to compound 
the breeding soundness examination index (BSE) for pigs with amplitude ranging from 100 to 1 and four classes (AE). There were differences in several seminal characteristics during the year within and between the farms in periods of higher temperature and temperature and humidity index. There were differences between the farms for MOT $(13.1 \pm 4.0$ vs. 12.0 \pm 3.6$)$, MORPH (35.5 \pm 11.4 vs. $27.6 \pm 11.6), \quad$ CONC $(21.6 \pm 16.8$ vs. $13.4 \pm 10.6)$ and $\operatorname{BSE}(70.2 \pm 21.5$ vs. $53.0 \pm 18.8)$, and the $\mathrm{BSE}$ class frequencies $\mathrm{A}=17.92 \%$ vs. $0.83 \%, \mathrm{~B}=13.75 \%$ vs. $21.25 \%, \mathrm{C}=16.67 \%$ vs. $21.67 \%, \mathrm{D}=1.25 \%$ vs. $4.17 \%$ and $\mathrm{E}=0.42 \%$ vs. $2.08 \%$ for $\mathrm{G} 1$ and $\mathrm{G} 2$ respectively.
Ejaculates presented season variations, with lesser quality during months with higher room temperature and temperature and humidity index. There were differences between and within farms. The air-conditioned farm (G1) presented better seminal characteristics along the year. The BSE means and its class frequencies reflected the seasonal variations of the ejaculates. There were correlations between BSE with the seminal characteristics, and artificial insemination doses showed variation in quality characteristics. There were seasonal deleterious effects on seminal characteristics of boars.

KEYWORDS: breeding soundness examination; humidity; semen; sperm morphology; swine; temperature.

\section{INTRODUÇÃO}

Embora a porca tenha considerável importância sobre a concepção, a influência do macho não pode ser ignorada, principalmente em razão da crescente utilização de programas de inseminação artificial. O reprodutor suíno determina quase $33 \%$ da fertilidade total do rebanho, sendo 15 vezes mais importante que a fertilidade da matriz suína isoladamente, e representa metade da influência do manejo reprodutivo em geral (FLOWERS, 1997).

O sêmen, a ser utilizado para a inseminação artificial deve apresentar características qualitativas e quantitativas que possibilitem o processamento de doses inseminantes, sem comprometimento da fertilidade. Estudos em diferentes latitudes e sistemas de manejo demonstraram o efeito da temperatura e umidade sobre a queda na produção e variações sobre a perda de qualidade na morfologia espermática, o que se refletia na fertilidade dos animais (WETTEMANN \& DEJARDINS 1979; WETTEMANN \& BAZER 1985; PELTONIEMI et al., 1999; SURIYASOMBOON et al., 2005), manifestando efeito da idade sendo que animeis jovens teriam maior resistência a estes efeitos (HUANG et al., 2010) . De acordo com LEVIS (1997), quando se expõem os machos a altas temperaturas (estresse calórico), após 7-15 dias desde a exposição, tem-se queda real da fertilidade (com diminuição da motilidade espermática e aumento das anormalidades espermáticas), que se normalizará aproximadamente após 60 dias.

Os diferentes procedimentos de avaliação de sêmen, como as avaliações da motilidade espermática progressiva, da concentração e da morfologia espermática e a combinação dos resultados dessas, expressam diversos estados da espermatogênese com prognósticos diferentes. Uma metodologia simples e rápida de avaliação do potencial de fertilidade de touros, o índice de capacidade andrológica por pontos para touros (CAP), poderia ser adaptado aos reprodutores suínos. O CAP foi empregado como critério de escolha de reprodutores bovinos por expressar, em uma escala, a capacidade potencial desses animais (VALE FILHO et al., 1997; FRENEAU et al., 2000). A utilização do CAP em suínos poderia facilitar a avaliação e a tomada de decisões em relação aos ejaculados e ao descarte de reprodutores, ao longo do período reprodutivo.

Objetivou-se com este trabalho avaliar a qualidade dos ejaculados de suínos sobre duas condições de alojamentos com o sem climatização, durante 12 meses.

\section{MATERIAL E MÉTODOS}

$\mathrm{O}$ experimento foi realizado em duas granjas que utilizam inseminação artificial, classificadas como granjas de reprodutores suínos e credenciadas como granja de reprodutores suínos certificada (distantes $57,7 \mathrm{~km}$ uma da outra), no período de março de 2001 a fevereiro de 2002. Uma granja localizava-se no município de Varjão - Goiás (G1), latitude sul de $17^{\circ} 02^{\prime} 43^{\prime \prime}$, longitude oeste de $49^{\circ}$ 37' 29" e altitude média de $609 \mathrm{~m}$.

Os machos foram mantidos em ambiente controlado com temperatura média de $23^{\circ} \pm 2^{\circ} \mathrm{C}$ e umidade relativa do ar entre $60-70 \%$ ao longo do período experimental, por meio de equipamento de resfriamento utilizado no tratamento com ventilação refrigerada.

A outra granja localizava-se no município de Indiara - Goiás (G2), latitude sul de $17^{\circ} 08^{\prime} 26^{\prime}$, longitude de $49^{\circ} 59^{\prime} 24^{\prime \prime}$ oeste e altitude média de $616 \mathrm{~m}$, onde os machos foram mantidos em construções de alvenaria, sem controle de temperatura e umidade. As temperaturas (máxima e mínima) foram registradas diariamente entre $12 \mathrm{e}$ 14h, na granja G2 com auxilio de termômetro de máxima e mínima de bulbo seco (Figura1). A 
umidade relativa do ar diária para a região referente ao período experimental foi considerada a registrada pelo Instituto Nacional de Meteorologia para a região (INMET, 2012). Com os dados de temperatura e unidade foi construído o índice de temperatura e umidade (ITU), segundo
BUFFINGTON et al. (1981), em que se associa a temperatura máxima de bulbo seco e a umidade relativa do ar. ITU $=0,8$. Tbs + UR(Tbs-14,3)/100 + 46,3. Em que: Tbs = temperatura máxima do bulbo seco, UR= umidade relativa do ar (Figura 2).

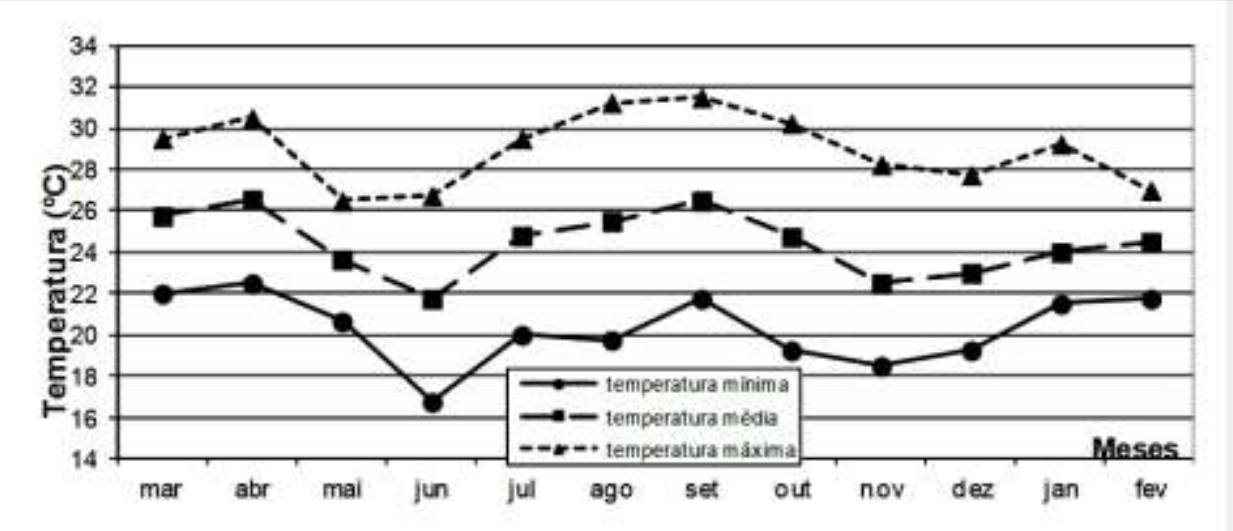

Figura 1. Temperaturas mínimas, médias e máximas observadas na granja 2, Microrregião do Vale dos Bois do estado de Goiás.

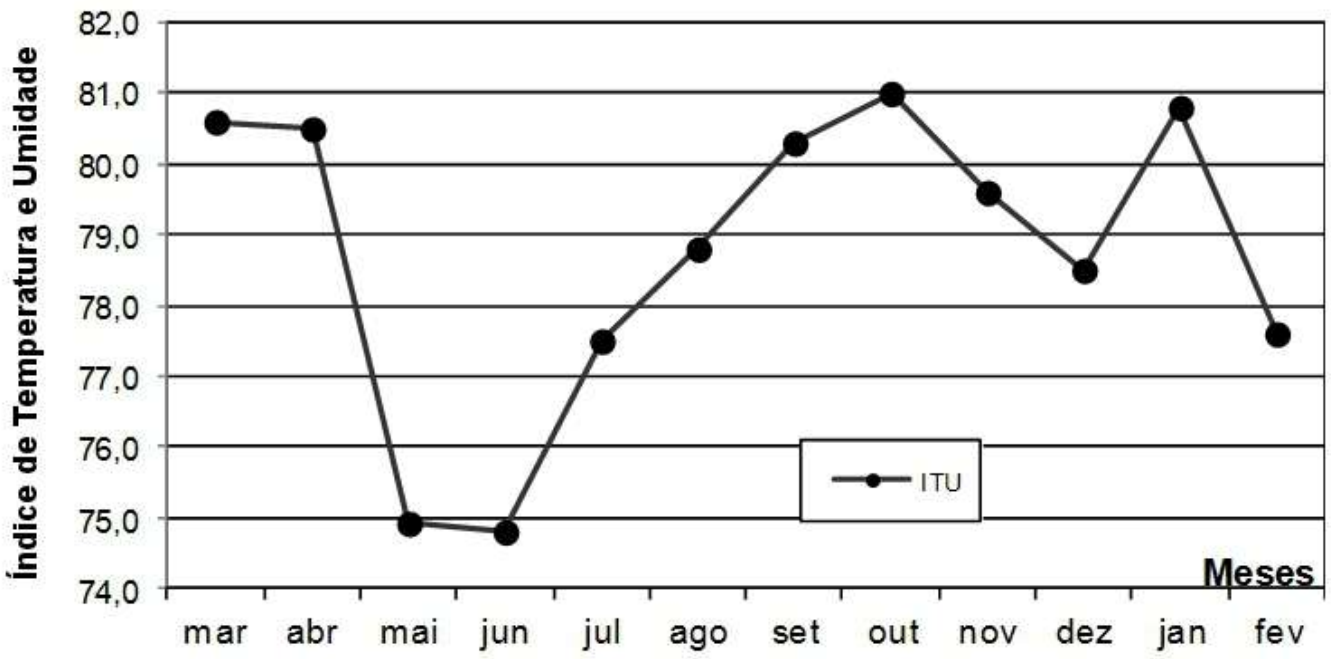

Figura 2. Índice de Temperatura e Umidade observadas na granja 2, Microrregião do Vale dos Bois do estado de Goiás.

Para este estudo, foram utilizados 10 machos suínos adultos, com idades entre 17 a 20 meses, da linha 409 da Agroceres Pic, com características de crescimento ponderal e clínico-andrológicas similares. Cinco animais foram mantidos em ambiente climatizado (G1) e cinco em ambiente não climatizado (G2). Os animais foram alimentados com ração balanceada formulada segundo o NRC (1998). As coletas de sêmen quinzenais (24/animal/ano) foram realizadas da mesma forma, conforme protocolo das granjas, de acordo com a técnica descrita pelo CBRA (1998). A fração rica em espermatozóides do ejaculado foi coletada em recipiente graduado de $500 \mathrm{ml}$ e protegida com um 
copo de isopor. O sêmen foi mantido em banhomaria a $37^{\circ} \mathrm{C}$, até a realização das análises de rotina da granja, tomada de amostras e processamento final para estocagem.

Foram realizadas as análises de aspectos físicos do sêmen. $\mathrm{O}$ volume, em $\mathrm{mL}$, foi medido com recipiente graduado. Com microscópio de fundo claro e 200x, foram avaliados o vigor (0-5) e a motilidade espermática progressiva (em porcentagem). Posteriormente, uma alíquota de sêmen foi diluída (1:10) em solução de citrato de sódio formolado para se verificar a concentração espermática (conc) em câmara de Newbauer, segundo técnica de rotina (CBRA, 1998). Outra alíquota de sêmen foi estocada em citrato de sódio formolado para posterior análise da morfologia espermática, realizada entre lâmina e lamínula em microscópio óptico de contraste diferencial de interferência de fase (1000x). Os defeitos espermáticos foram agrupados em defeitos maiores (Dma), menores (Dme) e totais (DT), segundo BLOM (1973). Com os dados dos aspectos físicos e morfológicos dos ejaculados, estabeleceu-se o CAP para suínos. A metodologia considerou as somas das pontuações da motilidade espermática (MOT), da morfologia espermática (MORF) e da concentração espermática $(\mathrm{CON})$. Os ejaculados foram divididos em classes de pontos (Tabela 1).

Tabela 1. Pontuações da morfologia espermática (MORF), da motilidade progressiva dos espermatozoides (MOT) e da concentração espermática (CONC) para estabelecimento do índice de capacidade andrológica por pontos para suínos (CAP)

\begin{tabular}{llllll}
\hline MORF & 40 pontos & 25 pontos & 10 pontos & 3 pontos & 1 ponto \\
\hline Defeitos maiores \% & $\leq 10,5$ & $11-19,5$ & $20-29,5$ & $30-39,5$ & $\geq 40$ \\
Defeitos totais \% & $\leq 24,5$ & $25-39,5$ & $40-59,5$ & 60 & $\geq 60,5$ \\
MOT & 20 pontos & 15 pontos & 10 pontos & 3 pontos & 1 ponto \\
Motilidade progressiva \% & $\geq 85$ & $84-75,5$ & $75-65,5$ & $65-60,5$ & $<60$ \\
CON & 40 pontos & 25 pontos & 10 pontos & 3 pontos & 1 ponto \\
Concentração espermática $\left(10^{6} / \mathrm{ml}\right)$ & $\geq 350$ & $349-300$ & $299-250$ & $249-150$ & $<149$ \\
\hline
\end{tabular}

Adaptado de FRENEAU et al. (2000)

A pontuação da MORF foi feita de acordo com a metodologia utilizada para bovinos (Tabela 1 ). As pontuações da MOT e da CON foram definidas de acordo com a análise da distribuição de frequência das avaliações realizadas ao longo dos 12 meses de experimento estimadas pela fórmula de Yule: $\mathrm{nc}=2,5 \operatorname{raiz}(\mathrm{N})$, onde: $\mathrm{nc}=$ número de classes e $\mathrm{N}=$ número de variáveis. Os resultados estão representados na Tabela1. Para a pontuação do CAP, considerou-se a soma de pontos das três características (MORF, MOT e CON). As cinco classes do CAP foram definidas de acordo com a seguinte pontuação: $\mathrm{A}=$ muito bom $(\geq 85$ pontos $)$; $\mathrm{B}$ = bom (64 a 84 pontos); $\mathrm{C}=$ regular com restrições (35 a 59 pontos); $\mathrm{D}=$ ruim (16 a 34 pontos) e $\mathrm{E}=$ péssimo (< 16 pontos) (FRENEAU et al., 2000).

Calcularam-se as doses inseminantes tradicionais (DTR) e as doses eficientes (DEF). Para as DTR, utilizadas rotineiramente nas granjas, considerou-se apenas a concentração espermática de $3 \times 10^{9}$ espermatozoides em doses de $100 \mathrm{~mL}$. Para as DEF, subtraiu-se o total das patologias espermáticas (Dma e Dme) e considerou-se, também, só a percentagem de espermatozoides com motilidade progressiva resultando em doses de $3 \times 10^{9}$ espermatozoides móveis e normais/100 mL. Para se avaliar a qualidade das doses inseminantes ao longo dos 12 meses, foram calculadas as diferenças entre o número de doses inseminantes produzidas (DIFD=DTR-DEF) e as porcentagens das DEF em relação às DTR (DPER=DEF/DTR*100).

Os dados de cada coleta quinzenal (médias para característica) foram compilados em um protocolo de processamento mensal. Os dados quantitativos e qualitativos foram analisados pelo pacote estatístico SAS (1997). Foram comparadas as médias das características estudadas entre as granjas e dentro de cada granja ao longo dos meses de colheita. As comparações foram realizadas pelas análises não paramétricas Kruskal-Wallis, usando-se o teste de Wilcoxon e, posteriormente, comparandose, pelo teste $\mathrm{t}$ de Student, as granjas e a as médias dentro de cada granja, segundo SAMPAIO (2002). A comparação das frequências foi analisada pelo teste do qui-quadrado. Para a análise das correlações entre as características estudadas, utilizou-se a correlação de Spearman, recomendada para dados não paramétricos, também segundo SAMPAIO (2002). Os resultados foram expressos em médias e desvio padrão e foram consideradas diferenças quando $\mathrm{P}<0,05$. 


\section{RESULTADOS E DISCUSSÃO}

Nas Figuras 1 e 2 estão representadas as temperaturas médias, máximas e mínimas e o índice de temperatura e umidade (ITU) observadas na G2, durante o período de estudo, em que se verifica uma tendência sazonal nos valores. Considerando os dados médios da G1, verificou-se que o ITU apresentou media de 70,4 $\pm 0,2$.

No inicio do experimento, não houve diferença entre as características seminais estudadas dos varrões dentro de cada granja; portanto, o grupo foi considerado homogêneo e representativo de cada situação.

A concentração espermática não diferiu entre as granjas $(\mathrm{P}>0,05)$; no entanto, o número de espermatozoides por ejaculado (SPTZ/EJ) foi maior $(\mathrm{P}<0,05)$ na $\mathrm{G} 2$ nos meses de julho, setembro e dezembro de 2001 (Figura 3). Os resultados observados na $\mathrm{G} 2$ foram diferentes dos relatados por WETTEMANN \& BAZER (1985) e
KUNAVONGKRIT \& PRATEEP (1995) que, ao submeteram os animais ao estresse térmico, verificaram diminuição da concentração quando a temperatura ambiente era elevada. Ao comparar as médias dentro das granjas, observou-se diminuição da concentração espermática $(\mathrm{P}<0,10)$, principalmente na G2, no mês de junho de 2001, provavelmente, em consequência das altas temperaturas e ITU às quais os animais foram submetidos no mês de abril (Figuras 1, 2 e 3).

Observou-se relação entre as médias das temperaturas máximas e a concentração espermática na G2, ao longo do período experimental, sendo as máximas temperaturas no local seguidas por coletas com menor concentração espermática (Figura 4). Desenho similar foi observado para o ITU (Figura 2). Esse fato confirma relatos prévios (KUNAVONGKRIT \& PRATEEP 1995; SURIYASOMBOON et al., 2004) de que o estresse térmico causa diminuição da concentração espermática por um período de até oito semanas.

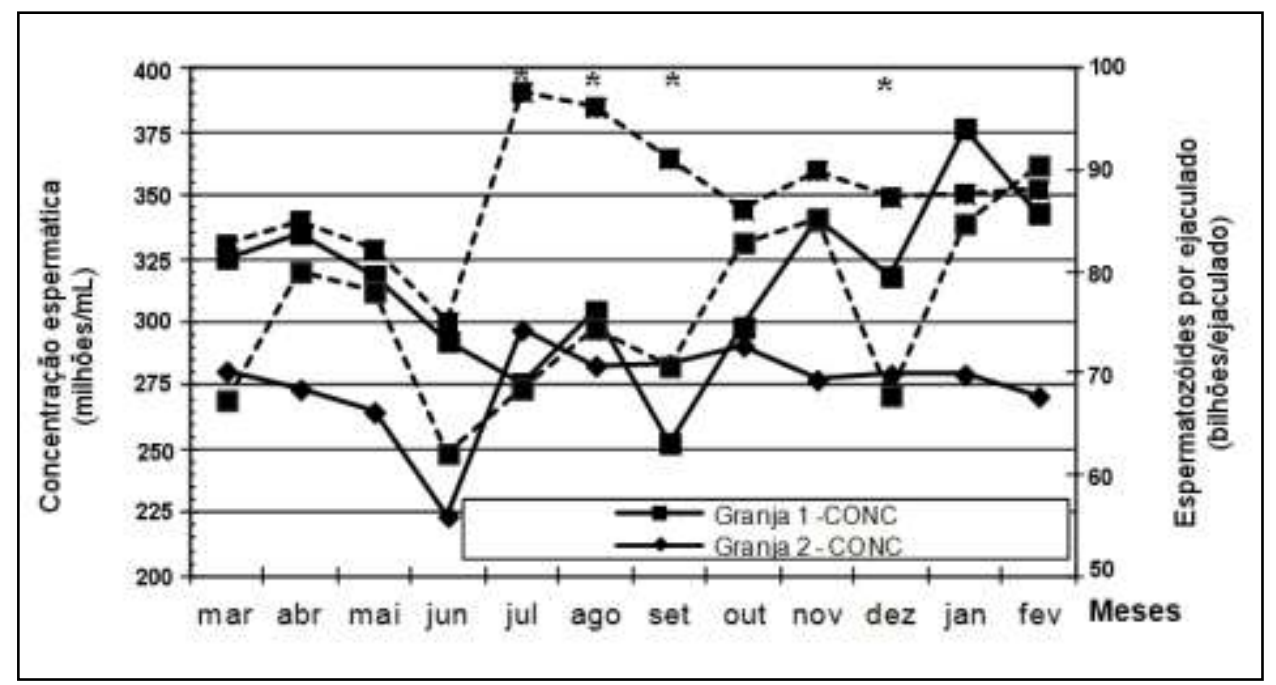

Figura 3. Concentração espermática (CONC) e espermatozoides/ejaculado (SPTZEJ) nos ejaculados de varrões em duas granjas de inseminação artificial (granja 1 climatizada e 2 não climatizada), Microrregião do Vale dos Bois do estado de Goiás, $(* \mathrm{P}<0,05)$.

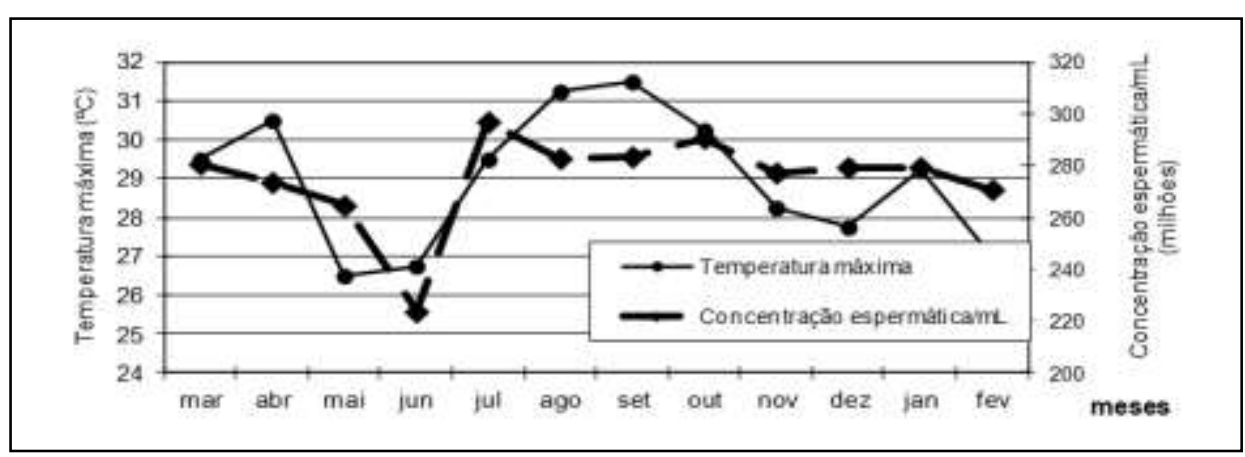

Figura 4. Temperatura máxima e concentração espermática/mL em ejaculados de varrões da granja 2 (não climatizada), Microrregião do Vale dos Bois do estado de Goiás. 


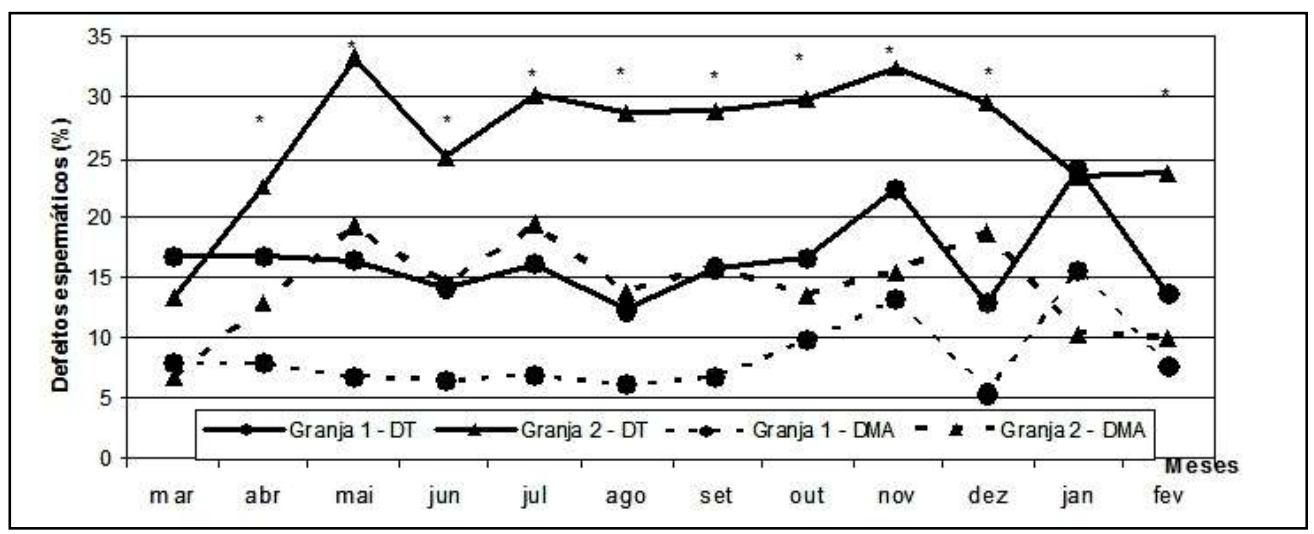

Figura 5. Defeitos espermáticos maiores (DMA) e totais (DT) em ejaculados de varrões de duas granjas de inseminação artificial (granja 1 climatizada e 2 não climatizada), Microrregião do Vale dos Bois do estado de Goiás $(*=\mathrm{p}<0,05)$.

Em relação à morfologia espermática, observou-se, na G2, maior porcentagem de Dma e DT $(\mathrm{P}<0,05)$, no período experimental. Isso demonstra que temperaturas ambientes e ITU elevados causaram aumento do número de espermatozoides anormais no ejaculado, principalmente nos meses de dezembro e maio de 2001, quando foram observadas as maiores médias de DT (Figura 5), provavelmente em decorrência das temperaturas e do ITU, registrados nos meses de abril, setembro e outubro do mesmo ano (Figuras 1, 2 e 5).

LEVIS (1997) relatou que, após 15 dias de exposição a altas temperaturas ambientes, os animais apresentaram aumento das anormalidades espermáticas, que só voltaram a valores normais depois de, aproximadamente, 60 dias. Esses fatos se justificam em razão do ciclo espermatogênico, em suínos, de 3539 dias, e aos 10-14 dias necessários ao trânsito epididimário para que os espermatozoides sejam ejaculados (ROBERTS, 1986). De acordo com WETTEMANN \& DEJARDINS (1979), a partir do início da exposição do suíno a altas temperaturas até o surgimento dos problemas relativos à qualidade seminal, existe um intervalo de cerca de duas semanas. Isso sugere que os espermatozoides do epidídimo são mais resistentes à exposição a altas temperaturas ambientes, quando comparados aos espermatozoides ainda nos testículos.

Segundo PELTONIEMI et al. (1999), altas temperaturas têm sido relacionadas à redução da fertilidade em rebanhos suínos, possivelmente, em razão dos efeitos negativos sobre a espermatogênese dos machos. Machos submetidos a temperaturas elevadas por vários dias sucessivos podem apresentar produção sub-ótima de sêmen por período de cinco a seis semanas, que corresponde à duração da espermatogênese, com reflexo sobre a qualidade seminal que pode durar de sete a oito semanas.

Resultados semelhantes, foram também observados por WETTEMANN \& DEJARDINS (1979), WETTEMANN \& BAZER (1985), LEVIS (1997), PELTONIEMI et al. (1999) e SURIYASOMBOON et al. (2005) HUANG et al. (2010) os quais relataram que altas temperaturas e umidade relativa ambientes prejudicam a espermatogênese e, consequentemente, diminuem o número de espermatozoides normais no ejaculado durante um período de até dois meses, trazendo prejuízos na produção de doses inseminantes. O que foi reportado como a possível infertilidade sazonal devido, pelo menos em parte, a uma combinação de baixa mobilidade, morfologia anormal incluindo anormalidade acrossomal, modulado por ua conbinacao de calor, umidade e fotoperíodo (MURASE et al. 2007). Em outras espécies como coelhos também foram reportados efeitos deletérios de maiores ITU em condições sazonais da região Mediterrânea da Espanha sobre os ejaculados representados pela menor porcentagem de espermatozoides normais e acrossomas sem observar efeitos do fotoperíodo (ROCA et al., 2005).

Essa redução na qualidade dos ejaculados poderia ser devido ao calor direto sobre o testículo interferindo na sua termorregulação. Outra possível causa relatada seria a menor ingestão de alimentos devido ao estresse calórico sofrido pelos animais (RINALDO et al., 2000) o que interferiria no processo espermatogênico.

As temperaturas máximas observadas na G2, nos meses de abril e agosto a outubro ultrapassaram $30^{\circ} \mathrm{C}$ (Figura 1). Paralelamente, o índice de temperatura e umidade (ITU) ultrapassou os 79 pontos nos meses de março, abril, de agosto a outubro e janeiro (Figura 2). Para a produção de suínos, SAMPAIO et al. (2004) relatam que valores acima de 70 de ITU causariam desconforto térmico. Temperaturas ambientes elevadas, superiores a $30^{\circ} \mathrm{C}$, causam alterações da qualidade e quantidade seminais 
de varrões (CHUNG-WEN et al., 1996). Dois animais (40\%) da granja G2, durante o mês de novembro de 2001, manifestaram quadros de degeneração testicular moderado, com elevada porcentagem de Dma $(27,5 \%$ e $37,5 \%$ ) e DT (43\% e $49 \%$ ), provocada, provavelmente, pelo estresse, principalmente, no mês de setembro de $2001 \mathrm{em}$ que se registraram as maiores temperaturas máximas e ITU acima de 70 (Figuras 1 e 2). Apesar de não computados, outros fatores como o tempo e a duração de temperaturas máximas pode ter contribuído para o quadro observado.

De acordo com AGROCERES (1996), o número de células anormais no ejaculado não pode exceder a $20 \%$. Maiores valores de patologias espermáticas podem ser admitidos. Já BONET (1990) admite patologias espermáticas totais inferiores a $25 \%$. Segundo ALM et, al, (2006) utilizando esta mesma metodologia de defeitos maiores e totais verificaram uma relação positiva entre a fertilidade e ejaculados com não mais de $30 \%$ de DT e negativa com os defeitos maiores. De acordo com os parâmetros considerados por esses autores, os ejaculados dos animais da G2, no mês de novembro de 2001, como citado anteriormente, deveriam ser afastados, temporariamente, do programa, já que na análise morfológica apresentaram valores de espermatozoides normais menores do que os ejaculados destinados à inseminação artificial.

Quanto à produção de doses inseminantes, as mesmas deveriam ser monitoradas de acordo com a MOT e a MORF e não somente em relação ao número de espermatozoides por ejaculado (SPTZ/EJ). Pôde-se concluir, neste experimento, que, se fossem considerados exclusivamente os SPTZ/EJ, a G2 (Figura 3) teria tido, em pelo menos três meses, animais de melhor produção de sêmen que a G1. NO entanto, essa conclusão sem monitoramento da MOT e da MORF seria omissa quanto à qualidade das doses produzidas.

Nos 240 ejaculados, as médias para os componentes do CAP foram de 12,5 $\pm 3,8,31,6 \pm 11,4 \mathrm{e}$ $17,5 \pm 14,6$ para MOT, MORF e CON, respectivamente, e de $61,6 \pm 21,9$ para o CAP total. Na G1 e G2 as médias foram, respectivamente, $13,1 \pm 4,0$ e $12,0 \pm 3,6$ para MOT, 35,5 $\pm 11,4$ e $27,6 \pm 11$ para MORF, $21,6 \pm 16,8$ e $13,4 \pm 10,6$ para CON e $70,2 \pm 21,5$ e $53,0 \pm 18,8$ para o CAP total. Observaram-se diferenças $(\mathrm{P}<0,001)$ entre as duas granjas (Tabela 2).

Tabela 2. Componentes do índice de capacidade andrológica (media e desvio padrão) por pontos para suínos (CAP), pontuações da motilidade (MOT), da concentração (CON), da morfologia espermática (MORF) e o CAP de duas granjas de inseminação artificial (G1 climatizada e G2 não climatizada), na Microrregião do Vale dos Bois do estado de Goiás.

\begin{tabular}{|c|c|c|c|c|c|c|c|c|}
\hline \multirow[b]{2}{*}{ Mês/ano } & \multicolumn{2}{|c|}{ MOT } & \multicolumn{2}{|c|}{ MORF } & \multicolumn{2}{|c|}{$\mathrm{CON}$} & \multicolumn{2}{|c|}{ CAP } \\
\hline & $\begin{array}{l}\text { Granja } 1 \\
(\mathrm{X} \pm \mathrm{DP})\end{array}$ & $\begin{array}{l}\text { Granja } 2 \\
(\mathrm{X} \pm \mathrm{DP})\end{array}$ & $\begin{array}{l}\text { Granja 1 } \\
(\mathrm{X} \pm \mathrm{DP})\end{array}$ & $\begin{array}{l}\text { Granja } 2 \\
(\mathrm{X} \pm \mathrm{DP})\end{array}$ & $\begin{array}{c}\text { Granja 1 } \\
(\mathrm{X} \pm \mathrm{DP})\end{array}$ & $\begin{array}{l}\text { Granja } 2 \\
(\mathrm{X} \pm \mathrm{DP})\end{array}$ & $\begin{array}{l}\text { Granja } 1 \\
(\mathrm{X} \pm \mathrm{DP})\end{array}$ & $\begin{array}{l}\text { Granja } 2 \\
(\mathrm{X} \pm \mathrm{DP})\end{array}$ \\
\hline 03/01 & $15,0 \pm 3,3 \mathrm{a} / \mathrm{A}$ & $13,0 \pm 2,6 \mathrm{a} / \mathrm{A}$ & $37,0 \pm 6,3 \mathrm{a} / \mathrm{AB}$ & $40,0 \pm 0,0 \mathrm{a} / \mathrm{A}$ & $28,7 \pm 18,2 \mathrm{a} / \mathrm{A}$ & $14,6 \pm 9,3 \mathrm{~b} / \mathrm{A}$ & $80,7 \pm 21,8 \mathrm{a} / \mathrm{A}$ & $67,6 \pm 9,4 \mathrm{a} / \mathrm{A}$ \\
\hline 04/01 & $12,5 \pm 2,6 \mathrm{a} / \mathrm{A}$ & $11,6 \pm 4,5 \mathrm{a} / \mathrm{A}$ & $37,0 \pm 6,3 \mathrm{a} / \mathrm{AB}$ & $33,1 \pm 12,9 \mathrm{a} / \mathrm{AB}$ & $27,2 \pm 17,8 \mathrm{a} / \mathrm{A}$ & $14,0 \pm 13,6 \mathrm{a} / \mathrm{A}$ & $76,7 \pm 20,4 \mathrm{a} / \mathrm{A}$ & $57,2 \pm 22,6 \mathrm{~b} / \mathrm{A}$ \\
\hline $05 / 01$ & $14,0 \pm 3,2 \mathrm{a} / \mathrm{A}$ & $10,4 \pm 5,0 \mathrm{a} / \mathrm{AB}$ & $37,0 \pm 6,3 \mathrm{a} / \mathrm{AB}$ & $29,5 \pm 16,1 \mathrm{a} / \mathrm{AB}$ & $22,7 \pm 18,5 \mathrm{a} / \mathrm{A}$ & $13,0 \pm 12,8 \mathrm{a} / \mathrm{A}$ & $73,7 \pm 18,7 \mathrm{a} / \mathrm{A}$ & $52,6 \pm 23,4 \mathrm{~b} / \mathrm{A}$ \\
\hline 06/01 & $14,5 \pm 3,7 \mathrm{a} / \mathrm{A}$ & $13,0 \pm 2,6 \mathrm{a} / \mathrm{A}$ & $37,0 \pm 6,3 \mathrm{a} / \mathrm{AB}$ & $25,8 \pm 10,1 \mathrm{~b} / \mathrm{AB}$ & $17,0 \pm 17,3 \mathrm{a} / \mathrm{A}$ & $6,9 \pm 7,4 \mathrm{a} / \mathrm{A}$ & $68,5 \pm 17,3 \mathrm{a} / \mathrm{A}$ & $45,7 \pm 13,8 \mathrm{~b} / \mathrm{A}$ \\
\hline 07/01 & $13,5 \pm 4,1 \mathrm{a} / \mathrm{A}$ & $10,6 \pm 4,1 \mathrm{a} / \mathrm{A}$ & $35,5 \pm 7,2 \mathrm{a} / \mathrm{AB}$ & $18,3 \pm 8,9 \mathrm{~b} / \mathrm{B}$ & $12,3 \pm 13,2 \mathrm{a} / \mathrm{A}$ & $16,9 \pm 12,8 \mathrm{a} / \mathrm{A}$ & $61,3 \pm 14,9 \mathrm{a} / \mathrm{A}$ & $45,8 \pm 21,1 \mathrm{~b} / \mathrm{A}$ \\
\hline 08/01 & $12,5 \pm 3,5 \mathrm{a} / \mathrm{A}$ & $10,6 \pm 4,6 \mathrm{a} / \mathrm{A}$ & $40,0 \pm 0,0 \mathrm{a} / \mathrm{A}$ & $21,3 \pm 1,1 \mathrm{~b} / \mathrm{B}$ & $21,2 \pm 17,5 \mathrm{a} / \mathrm{A}$ & $13,8 \pm 8,0 \mathrm{a} / \mathrm{A}$ & $73,7 \pm 16,9 \mathrm{a} / \mathrm{A}$ & $45,7 \pm 20,3 \mathrm{~b} / \mathrm{A}$ \\
\hline 09/01 & $12,6 \pm 5,7 \mathrm{a} / \mathrm{A}$ & $12,5 \pm 2,6 \mathrm{a} / \mathrm{A}$ & $38,5 \pm 4,7 \mathrm{a} / \mathrm{AB}$ & $28,1 \pm 14,9 \mathrm{~b} / \mathrm{AB}$ & $12,5 \pm 13,0 \mathrm{a} / \mathrm{A}$ & $13,9 \pm 12,2 \mathrm{a} / \mathrm{A}$ & $63,6 \pm 18,6 \mathrm{a} / \mathrm{A}$ & $54,5 \pm 22,4 \mathrm{a} / \mathrm{A}$ \\
\hline $10 / 01$ & $13,1 \pm 5,1 \mathrm{a} / \mathrm{A}$ & $13,5 \pm 2,4 \mathrm{a} / \mathrm{A}$ & $33,3 \pm 12,3 \mathrm{a} / \mathrm{AB}$ & $25,0 \pm 7,1 \mathrm{a} / \mathrm{AB}$ & $22,2 \pm 17,5 \mathrm{a} / \mathrm{A}$ & $16,1 \pm 9,7 \mathrm{a} / \mathrm{A}$ & $68,6 \pm 23,1 \mathrm{a} / \mathrm{A}$ & $54,6 \pm 9,4 \mathrm{a} / \mathrm{A}$ \\
\hline $11 / 01$ & $11,3 \pm 3,8 \mathrm{a} / \mathrm{A}$ & $10,4 \pm 5,0 \mathrm{a} / \mathrm{A}$ & $29,6 \pm 15,3 \mathrm{a} / \mathrm{AB}$ & $24,9 \pm 15,6 \mathrm{a} / \mathrm{AB}$ & $22,1 \pm 16,5 \mathrm{a} / \mathrm{A}$ & $13,9 \pm 12,2 \mathrm{a} / \mathrm{A}$ & $63,0 \pm 22,2 \mathrm{a} / \mathrm{A}$ & $49,2 \pm 26,4 \mathrm{a} / \mathrm{A}$ \\
\hline $12 / 01$ & $14,5 \pm 2,8 \mathrm{a} / \mathrm{A}$ & $12,5 \pm 2,6 \mathrm{a} / \mathrm{A}$ & $40,0 \pm 0,0 \mathrm{a} / \mathrm{A}$ & $23,5 \pm 7,5 \mathrm{~b} / \mathrm{B}$ & $21,4 \pm 15,7 \mathrm{a} / \mathrm{A}$ & $12,4 \pm 9,2 \mathrm{a} / \mathrm{A}$ & $75,9 \pm 17,8 \mathrm{a} / \mathrm{A}$ & $48,4 \pm 11,9 \mathrm{~b} / \mathrm{A}$ \\
\hline $01 / 02$ & $9,9 \pm 4,8 \mathrm{a} / \mathrm{A}$ & $13,0 \pm 2,6 \mathrm{a} / \mathrm{A}$ & $25,9 \pm 35,5 \mathrm{a} / \mathrm{B}$ & $32,5 \pm 7,9 \mathrm{a} / \mathrm{AB}$ & $25,9 \pm 18,3 \mathrm{a} / \mathrm{A}$ & $13,9 \pm 9,9 \mathrm{a} / \mathrm{A}$ & $61,7 \pm 34,5 \mathrm{a} / \mathrm{A}$ & $59,4 \pm 16,9 \mathrm{a} / \mathrm{A}$ \\
\hline $02 / 02$ & $13,5 \pm 3,4 \mathrm{a} / \mathrm{A}$ & $13,0 \pm 2,6 \mathrm{a} / \mathrm{A}$ & $35,5 \pm 10,1 \mathrm{a} / \mathrm{AB}$ & $31,0 \pm 7,7 \mathrm{a} / \mathrm{AB}$ & $26,6 \pm 17,5 \mathrm{a} / \mathrm{A}$ & $11,0 \pm 10,5 \mathrm{~b} / \mathrm{A}$ & $75,6 \pm 25,2 \mathrm{a} / \mathrm{A}$ & $55,0 \pm 15,1 \mathrm{~b} / \mathrm{A}$ \\
\hline Total / granja & $13,1 \pm 4,0 \mathrm{a}$ & $12,0 \pm 3,6 \mathrm{a}$ & $35,5 \pm 11,4 \mathrm{a}$ & $27,6 \pm 11 \mathrm{~b}$ & $21,6 \pm 16,8$ a & $13,4 \pm 10,6 \mathrm{~b}$ & $70,2 \pm 21,5 \mathrm{a}$ & $53,0 \pm 18,8 \mathrm{~b}$ \\
\hline
\end{tabular}

Valores seguidos por letras minúsculas distintas indicam diferenças entre as granjas. Valores seguidos por letras maiúsculas distintas indicam diferenças dentro as granjas, pelo teste não paramétrico de Kruskal-Wallis/Wilcoxon. 
Na Tabela 2 são apresentados os componentes do CAP por granja ao longo do período experimental. Não houve diferença $(\mathrm{P}>0,05) \mathrm{em}$ $\mathrm{CON}$ entre as granjas, mas o CAP na granja G2 foi inferior $(\mathrm{P}<0,05)$ ao a da $\mathrm{G} 1$ nos meses de março de 2001 e fevereiro de 2002 (Tabela 2 e Figura 5), o que indica menor número de espermatozoides no ejaculado de suínos submetidos a fatores estressantes, como altas temperaturas. Resultados semelhantes foram também relatados por WETTEMANN \& BAZER (1985) e KUNAVONGKRIT \& PRATEEP (1995).

A MORF observada na granja G1 foi superior $(\mathrm{P}<0,05)$ nos meses de junho, julho, agosto, setembro e dezembro de 2001 (Tabela 2) e semelhante aos da G2 nos demais meses. À exceção da gota citoplasmática proximal, não houve patologia espermática individual que se destacasse mais frequentemente. As patologias espermáticas aumentaram de forma constante nos períodos posteriores a temperaturas e índice de temperatura e umidade elevados. Os defeitos maiores apresentaram padrão de elevação mais constante que os defeitos menores. Na granja G1, em janeiro de 2002, verificou-se que $20 \%$ dos ejaculados apresentaram elevado número de anormalidades espermáticas, e que nesse mês a MORF foi menor $(\mathrm{P}<0,05)$ do que a dos meses de agosto e dezembro de 2001. Os resultados da G1 mostraram que a climatização minimiza as possíveis interferências de altas temperaturas no processo espermatogênico. A G2 apresentou, nos meses de julho, agosto e dezembro de 2001, MORF menor do que a do mês de março de 2001 e semelhante aos demais meses (Tabela 2). Altas temperaturas prejudicaram a espermatogênese e aumentaram o número de espermatozoides anormais do ejaculado, o que causou diminuição da MORF.

Os CAP da G1 foram maiores $(\mathrm{P}<0,05)$ do que os da G2 nos meses de abril, maio, junho, julho, agosto e dezembro de 2001 e fevereiro de 2002 (Tabela 2 e Figura 6). Observou-se menor qualidade do sêmen em períodos posteriores (a partir de 30 dias) à ocorrência de altas temperaturas ambientais e índices de temperatura e umidade acima de 70. Pela diferença do CAP entre as granjas verificou-se que os machos da G1 apresentaram melhores parâmetros de qualidade seminal. Os machos da G2 apresentaram incremento na porcentagem de espermatozoides com defeitos e diminuição da qualidade dos ejaculados em consequência das altas temperaturas ambientais e índices de temperatura e umidade aos que foram submetidos em alguns meses. O decréscimo da qualidade do sêmen de suínos submetido ao estresse climático poderia ser, entre outros fatores, consequência da alteração da produção espermática e biossíntese de andrógenos testiculares, o que provocaria supressão parcial da maturação espermática, mudanças no plasma seminal com aumento de reação acrossomica (ROBERTS, 1986; BONET et al., 1995; MURASE et al., 2007).

Houve correlações altas e positivas $(\mathrm{p}<0,001)$ entre o CAP e seus componentes (MOT, CON e MORF) (Tabela 3). Os índices de MOT foram menores provavelmente em decorrência da variabilidade da característica, relacionando-se com estudos na espécie bovina. Foram observadas elevadas correlações negativas entre as características que compõem o CAP com Dma e os DT. Correlações elevadas e negativas entre o CAP e os Dma e DT foram, também, relatadas na espécie bovina (FRENEAU, 1996; CHENOWETH et al., 1996; VALE FILHO et al., 1997).

Como constatado na evolução dos ejaculados dos varrões, as temperaturas máximas e mínimas junto com o índice de temperatura e umidade foram correlacionados negativamente com a CONC, CAP, MORF e CON e positivamente com DMA e DT (Tabela 3), apesar de os suínos terem um bom poder de adaptação a condições constantes (SURIYASOMBOON et al., 2005). Essa constatação justifica-se pelo observado na granja G2, em que se verificaram maiores amplitudes de variações diárias de temperatura e índice de temperatura e umidade durante vários meses. Quando as variações de temperatura ultrapassam $10^{\circ} \mathrm{C}$ em condições de umidade (índice de temperatura e umidade acima de 70), elas provocam estresse, o que dificulta a adaptação desses animais (G 2). Portanto a flutuação de temperatura entre dia e noite pode ser um fator estressor durante os meses quentes do ano (KUNAVONGKRIT et al., 2005).

Observaram-se ejaculados enquadrados em todas as faixas do CAP (Tabela 4), porém, 95,5\% dos animais categorizados como de CAP muito bom (A) pertenciam à G1. Dos animais categorizados em $\mathrm{D}$ (ruins) e E (péssimos), 76,9\% e 83,3\%, respectivamente, pertenciam à $\mathrm{G} 2$. 


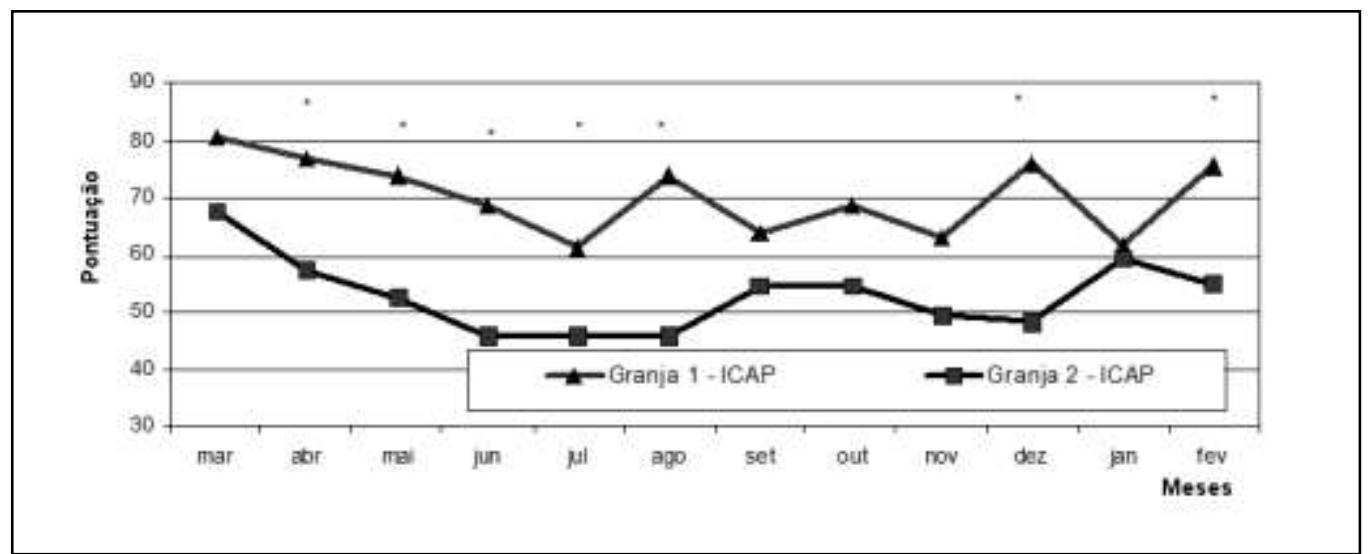

Figura 6. Índice de capacidade andrológica por pontos (CAP) para suínos de duas granjas de inseminação artificial (G1 climatizada e G2 não climatizada), Microrregião do Vale dos Bois do estado de Goiás $(* \mathrm{P}<0,05)$.

Tabela 3. Correlações de Spearman entre características seminais, componentes do CAP, temperaturas máximas e mínimas, morfologia espermática, doses tradicionais, doses ideais e suas diferenças absoluta e percentual em varrões de duas granjas de inseminação artificial (G1 climatizada e G2 não climatizada), Microrregião do Vale dos Bois do estado de Goiás

\begin{tabular}{l|cccccccccccccccccc}
\hline & MOT MORF & CON & CAP & Tmin & Tmax & ITU & motil & conc & Gcp & Dme & Dma & Dt & DTR & DEF DIFD DPER \\
\hline MOT & - & 0,50 & 0,11 & 0,51 & $-0,14$ & $\mathrm{~ns}$ & $\mathrm{~ns}$ & 0,96 & $\mathrm{~ns}$ & $-0,61$ & $\mathrm{~ns}$ & $-0,56$ & $-0,48$ & $\mathrm{~ns}$ & 0,37 & $-0,53$ & 0,70 \\
MORF & - & - & 0,20 & 0,74 & $-0,32$ & $-0,30$ & $-0,31$ & 0,56 & 0,16 & $-0,79$ & $-0,36$ & $-0,85$ & $-0,85$ & $\mathrm{~ns}$ & 0,40 & $-0,69$ & 0,85 \\
COM & - & - & - & 0,79 & $-0,28$ & $-0,22$ & $-0,29$ & $\mathrm{~ns}$ & 0,91 & $-0,12$ & $-0,21$ & $-0,16$ & $-0,23$ & 0,48 & 0,53 & 0,14 & 0,22 \\
CAP & - & - & - & - & $-0,38$ & $-0,33$ & $-0,40$ & 0,52 & 0,70 & $-0,60$ & $-0,34$ & $-0,64$ & $-0,67$ & 0,26 & 0,63 & $-0,35$ & 0,71 \\
Tmin & - & - & - & - & - & 0,90 & 0,83 & $-0,12$ & $-0,22$ & 0,17 & 0,43 & 0,26 & 0,41 & 0,26 & $\mathrm{~ns}$ & 0,44 & $-0,38$ \\
Tmax & - & - & - & - & - & - & 0,87 & $\mathrm{~ns}$ & $-0,18$ & 0,15 & 0,37 & 0,22 & 0,35 & 0,26 & $\mathrm{~ns}$ & 0,40 & $-0,33$ \\
ITU & - & - & - & - & - & - & - & $\mathrm{ns}$ & $-0,24$ & 0,20 & 0,44 & 0,27 & 0,40 & 0,25 & $\mathrm{~ns}$ & 0,45 & 0,37 \\
motil & - & - & - & - & - & - & - & - & $\mathrm{ns}$ & $-0,69$ & $\mathrm{~ns}$ & $-0,63$ & $-0,54$ & $\mathrm{~ns}$ & 0,40 & $-0,57$ & 0,75 \\
conc & - & - & - & - & - & - & - & - & - & $\mathrm{ns}$ & $-0,17$ & $-0,13$ & $-0,19$ & 0,54 & 0,56 & 0,21 & 0,19 \\
Gcp & - & - & - & - & - & - & - & - & - & - & $\mathrm{ns}$ & 0,88 & 0,76 & $\mathrm{~ns}$ & $-0,38$ & 0,66 & $-0,81$ \\
Dme & - & - & - & - & - & - & - & - & - & - & - & 0,18 & 0,62 & $\mathrm{~ns}$ & $-0,26$ & 0,40 & $-0,52$ \\
Dma & - & - & - & - & - & - & - & - & - & - & - & - & 0,88 & $\mathrm{~ns}$ & $-0,43$ & 0,71 & $-0,88$ \\
Dt & - & - & - & - & - & - & - & - & - & - & - & - & - & $\mathrm{ns}$ & $-0,47$ & 0,76 & $-0,95$ \\
DTR & - & - & - & - & - & - & - & - & - & - & - & - & - & - & 0,81 & 0,67 & $\mathrm{~ns}$ \\
DEF & - & - & - & - & - & - & - & - & - & - & - & - & - & - & - & $\mathrm{ns}$ & 0,50 \\
DIFD & - & - & - & - & - & - & - & - & - & - & - & - & - & - & - & - & $-0,78$ \\
DPER & - & - & - & - & - & - & - & - & - & - & - & - & - & - & - & - & - \\
\hline
\end{tabular}

$\overline{\mathrm{CAP}}=$ Índice de capacidade andrológica para suínos; $\mathrm{MOT}$ = pontuação pela motilidade progressiva no CAP; $\mathrm{MORF}=$ pontuação pela morfologia espermática no CAP; $\mathrm{CON}=$ pontuação pela concentração espermática CAPs; Tmin e Tmax = Temperaturas mínima e máxima; ITU = índice de temperatura e umidade; motil = motilidade individual progressiva; conc = concentração espermática; Gcp = gota citoplasmática proximal; Dme, Dma e DT = defeitos espermáticos menores maiores e totais; DTR $=$ doses inseminantes tradicionais; DEF $=$ doses inseminantes eficientes; DIFD = diferenças entre DTR e DEF; DPER = diferença percentual entre DTR e DEF. P<0,001, ns =não significativo. 
Tabela 4. Frequência de ejaculados de varrões avaliados pela capacidade andrológica por pontos para suínos (CAP) de duas Granjas de inseminação artificial (G1 climatizada e G2 não climatizada), Microrregião do Vale dos Bois do estado de Goiás

\begin{tabular}{|c|c|c|c|c|c|c|c|c|c|c|}
\hline \multirow{3}{*}{ Granjas } & \multicolumn{10}{|c|}{ Faixas do CAP } \\
\hline & \multicolumn{2}{|c|}{ A } & \multicolumn{2}{|c|}{ B } & \multicolumn{2}{|c|}{$\mathrm{C}$} & \multicolumn{2}{|c|}{ D } & \multicolumn{2}{|c|}{ E } \\
\hline & $\%$ & $\mathrm{n}$ & $\%$ & $\mathrm{n}$ & $\%$ & $\mathrm{n}$ & $\%$ & $\mathrm{n}$ & $\%$ & $\mathrm{n}$ \\
\hline G1 & 17,92 & 43 & 13,75 & 33 & 16,67 & 40 & 1,25 & 3 & 0,42 & 1 \\
\hline G2 & 0,83 & 2 & 21,25 & 51 & 21,67 & 52 & 4,17 & 10 & 2,08 & 5 \\
\hline Total & 18,75 & 45 & 35,00 & 84 & 38,33 & 92 & 5,42 & 13 & 2,50 & 6 \\
\hline
\end{tabular}

$\mathrm{A}=$ muito bom ( $\geq 85$ pontos); $\mathrm{B}=$ bom (64 a 84 pontos); $\mathrm{C}=$ regular com restrições ( 35 a 59 pontos); $\mathrm{D}=$ ruim $(16$ a 34 pontos) e $\mathrm{E}$ = péssimo $(<16$ pontos $)($ FRENEAU, et al 2000). Qui quadrado $\mathrm{P}<0,001$.

Em todos os meses do ano, G1 apresentou animais com CAP na classe $\mathrm{A}$, que variou de $60 \%$ em março a 10\% em julho de 2001 (Tabela 5). A G2, no mês de junho de 2001, apresentou $80 \%$ dos animais na classe $\mathrm{C}$ (regular com restrições) e nos meses de agosto, setembro e novembro $20-30 \%$ dos animais estavam com problemas reprodutivos (classe D), coincidindo com os meses de maior temperatura ambiente e índice de temperatura e umidade. Um animal da G2, nos meses de abril, maio, junho e novembro de 2001 e janeiro de 2002, apresentou problemas de degeneração testicular. Ressalta-se que, em touros, as faixas A e B são consideradas como as ideais para a formação de grupos em estação de acasalamento, descartando-se os touros da classe D (FRENEAU et al., 2000). As variações entre e dentro de cada granja, ao longo do período experimental, acompanharam os dados das características seminais isoladas.

Os efeitos negativos das altas temperaturas e umidade sobre a espermatogênese, com aumento do número das anormalidades espermáticas e, possivelmente, consequente redução do número de doses inseminantes por ejaculado, pode causar prejuízos financeiros para a granja, pela necessidade de se aumentar o número de machos para atender a demanda de doses inseminantes. Esses fatos deveriam ser considerados, quando da manipulação de ejaculados destinados à inseminação artificial, nas diferentes épocas do ano, principalmente, em granja com galpão não climatizado. A utilização de ejaculados com altos percentuais de patologia espermática poderia reduzir o número de leitões por nascimento, mesmo em doses heterospérmicas.

Desta forma, o controle externo da qualidade do sêmen em laboratórios de referência pode ser útil para monitorar a eficiência do controle interno da qualidade seminal em centrais de isnseminacao artificial, para identificar os cachaços com baixa qualidade dos ejaculados (WABERSKI et al., 2008). Os testes in vitro que medem características univariadas de ejaculados como motilidade e morfologia espermatica são precisos na previsão da fertilidade (FLOWERS, 2009) e portanto debveriam ser utilizados como forma de verificar os animais com ejaculados conciderados de fertilidade reduzida em diferentes epocas do ano dentro das granjas com inseminação artificial.

O número potencial de doses produzidas, ao longo do período de estudo, foi 6536 para GI e 4304 para $\mathrm{G} 2$, o que correspondeu às médias por ejaculado de $27,2 \pm 7,0$ e $16,4 \pm 5,3$, para as DTR e DEF, respectivamente. A diferença entre as duas modalidades de cálculo na produção de doses (DIFD) foi $10,8 \pm 4,2$, o que resultou em $60,4 \pm 10,9 \%$ das doses DEF sobre as DTR (DPER). Os dados observados para as granjas G1 e G2 para as DTR foram iguais a 25,2 $\pm 8,3$ e $29,1 \pm 4,9 \quad(\mathrm{P}<0,05)$, $16,4 \pm 6,0$ e $16,3 \pm 4,4(\mathrm{P}>0,05)$ para as DEF e $8,9 \pm 3,7$ e $12,8 \pm 3,7(\mathrm{P}<0,05)$ para as DIFD, respectivamente. Observou-se um aproveitamento de $64,8 \pm 8,9 \%$ e $56,1 \pm 11,0 \%$ das DEF/DTR $(\mathrm{P}<0,05)$ nas $\mathrm{G} 1$ e G2, respectivamente. A DIFD mostrou que na G1 foi produzido maior número de doses quando seus cálculos foram realizados considerando-se a qualidade dos ejaculados. Na avaliação das doses inseminantes produzidas nas granjas pelo sistema tradicional (DTR) e as eficientes (DEF), verificaramse diferenças significativas ao longo do experimento e foram observados coeficientes de correlação elevados e positivos entre o CAP e as $\operatorname{DEF}(r=0,63)$ e o percentual de DEF/DTR (DPER) $(\mathrm{r}=0,71)$, e 
correlações negativas $(r=-0,35)$ entre as diferenças entre doses tradicionais e eficientes produzidas (DIFD), respectivamente (Tabela 3). Esse resultado mostra que, quando o objetivo foi a produção de doses inseminantes de melhor qualidade, o número de DEF na G1 foi maior. Neste estudo, não foi possível verificar se essas diferenças na qualidade das doses ou se as diferenças nos ejaculados de menor qualidade, nos meses menos favoráveis, produziram algum impacto na produção de leitões nas duas granjas. Isso não foi possível em razão de terem sido utilizadas doses inseminantes com sêmen de vários machos e rotações de machos na segunda inseminação do cio observado nos dois sistemas de produção.

Tabela 5. Frequência de varrões por classe do índice de capacidade andrológica por pontos para suínos (CAP) de duas granjas de inseminação artificial (G1 climatizada e G2 não climatizada), na Microrregião do Vale dos Bois do estado de Goiás

\begin{tabular}{|c|c|c|c|c|c|c|c|c|c|c|c|}
\hline \multirow{3}{*}{ Meses/ano } & \multirow{3}{*}{ Granjas } & \multicolumn{10}{|c|}{ Faixas do CAP } \\
\hline & & \multicolumn{2}{|l|}{$\mathrm{A}$} & \multicolumn{2}{|l|}{$\mathrm{B}$} & \multicolumn{2}{|c|}{$\mathrm{C}$} & \multicolumn{2}{|l|}{$\mathrm{D}$} & \multicolumn{2}{|l|}{$E$} \\
\hline & & $\%$ & $\mathrm{n}$ & $\%$ & $\mathrm{n}$ & $\%$ & $\mathrm{n}$ & $\%$ & $\mathrm{n}$ & $\%$ & $\mathrm{~N}$ \\
\hline \multirow{2}{*}{ Março/2001 } & 1 & 60 & 6 & 10 & 1 & 30 & 3 & 0 & 0 & 0 & 0 \\
\hline & 2 & 0 & 0 & 80 & 8 & 20 & 2 & 0 & 0 & 0 & 0 \\
\hline \multirow{2}{*}{ Abril/2001 } & 1 & 50 & 5 & 20 & 2 & 30 & 3 & 0 & 0 & 0 & 0 \\
\hline & 2 & 10 & 1 & 40 & 4 & 40 & 4 & 0 & 0 & 10 & 1 \\
\hline \multirow{2}{*}{ Maio/2001 } & 1 & 40 & 4 & 40 & 4 & 20 & 2 & 0 & 0 & 0 & 0 \\
\hline & 2 & 10 & 1 & 20 & 2 & 50 & 5 & 10 & 1 & 10 & 1 \\
\hline \multirow{2}{*}{ Junho/2001 } & 1 & 20 & 2 & 40 & 4 & 40 & 4 & 0 & 0 & 0 & 0 \\
\hline & 2 & 0 & 0 & 10 & 1 & 80 & 8 & 0 & 0 & 10 & 1 \\
\hline \multirow{2}{*}{ Julho/2001 } & 1 & 10 & 1 & 30 & 3 & 60 & 6 & 0 & 0 & 0 & 0 \\
\hline & 2 & 0 & 0 & 40 & 4 & 40 & 4 & 10 & 1 & 10 & 1 \\
\hline \multirow{2}{*}{ Agosto/2001 } & 1 & 40 & 4 & 40 & 4 & 20 & 2 & 0 & 0 & 0 & 0 \\
\hline & 2 & 0 & 0 & 30 & 3 & 40 & 4 & 30 & 3 & 0 & 0 \\
\hline \multirow{2}{*}{ Setembro/2001 } & 1 & 20 & 2 & 30 & 3 & 40 & 4 & 10 & 1 & 0 & 0 \\
\hline & 2 & 0 & 0 & 60 & 6 & 20 & 2 & 20 & 2 & 0 & 0 \\
\hline \multirow{2}{*}{ Outubro/2001 } & 1 & 30 & 3 & 20 & 2 & 50 & 5 & 0 & 0 & 0 & 0 \\
\hline & 2 & 0 & 0 & 40 & 4 & 60 & 6 & 0 & 0 & 0 & 0 \\
\hline \multirow{2}{*}{ Novembro/2001 } & 1 & 30 & 3 & 30 & 3 & 40 & 4 & 0 & 0 & 0 & 0 \\
\hline & 2 & 0 & 0 & 50 & 5 & 20 & 2 & 20 & 2 & 10 & 1 \\
\hline \multirow{2}{*}{ Dezembro/2001 } & 1 & 30 & 3 & 40 & 4 & 30 & 3 & 0 & 0 & 0 & 0 \\
\hline & 2 & 0 & 0 & 30 & 3 & 60 & 6 & 10 & 1 & 0 & 0 \\
\hline \multirow{2}{*}{ Janeiro/2001 } & 1 & 50 & 5 & 0 & 0 & 30 & 3 & 10 & 1 & 10 & 1 \\
\hline & 2 & 0 & 0 & 60 & 6 & 40 & 4 & 0 & 0 & 0 & 0 \\
\hline \multirow{2}{*}{ Fevereiro/2001 } & 1 & 50 & 5 & 30 & 3 & 10 & 1 & 10 & 1 & 0 & 0 \\
\hline & 2 & 0 & 0 & 50 & 5 & 50 & 5 & 0 & 0 & 0 & 0 \\
\hline Total & & 18,7 & 45 & 35,00 & 84 & 38,33 & 92 & 5,42 & 13 & 2,50 & 06 \\
\hline
\end{tabular}

$\mathrm{A}=$ muito bom ( $\geq 85$ pontos); $\mathrm{B}=$ bom (64 a 84 pontos); $\mathrm{C}=$ regular com restrições ( 35 a 59 pontos); $\mathrm{D}=$ ruim (16 a 34 pontos) e $\mathrm{E}$ $=$ péssimo $(<16$ pontos $)$ (FRENEAU, et al 2000). Qui quadrado $\mathrm{P}<0,05$.

\section{CONCLUSÕES}

A avaliação dos aspectos morfológicos de ejaculados de suínos apresentaram variações, com menor qualidade nos meses de maior temperatura e índice de temperatura e umidade. A granja climatizada apresentou melhores parâmetros seminais ao longo do ano. As médias do CAP e as frequências de ejaculados dentro das classes do CAP refletiram as variações sazonais dos ejaculados. Da mesma forma, as doses inseminantes apresentaram variações em número quando se consideraram as características de qualidade dos ejaculados 


\section{AGRADECIMENTOS}

Suporte financeiro da Fundação de Apoio à Pesquisa e Empresas do Setor. Os autores agradecem aos Professores Emilio A. Martinez Garcia e Jordi A. Roca da Universidade de Murcia, pela revisão crítica do manuscrito.

\section{REFERÊNCIAS}

AGROCERES. Manual de inseminação de suínos. Depto. De Serviços Veterinários. Agroceres, Divisão Animal, 51.p. 1996.

ALM, K., PELTONIEMI, OAT, KOSKINEN, E., ANDERSSON, M. Porcine Field Fertility with Two Different Insemination Doses and the Effect of Sperm Morphology. Reproduction Domestic Animal, v. 41, p. 210-213, 2006.

BLOM, E. The ultrastructure of some characteristics sperm defects and a proposal for a new classification on the bull spermiogram. Nordisk Veterinaermedicin., v. 25, n. 7-8, p.383-391, 1973.

BONET, S.; BRIZ, M.; FRADERA, A. Estudo comparativo entre a morfologia espermática do ejaculado de varrascos submetidos a colheitas do sémen cada dois dias e a morfologia do sémen procedente das três regiões epididimárias. Revista Técnica de Suinocultura, v. 11, n. 2, p.1-9, 1995.

BONET, S. Immature and aberrant spermatozoa in the ejaculate of Sus domesticus. Animal Reproduction Science, v. 22, p.67-80, 1990.

BUFFINGTON, D.E. COLLAZO-AROCHO, A.; CANTON, G.H., PITT, D. THATCHER, W. W. COLLIER, R. J. Black globe-humidity index (BGHI) as comfort equation for dairy cows. Applied Engineering in Agriculture, v.24, n. 3, p.711-714, 1981.

CHENOWETH, P.J.; CHASE JR., C.C.; THATCHER, M.J.D. Breed and other effects on reproductive traits and breeding soundness categorization in young bulls in Florida. Theriogenology, v. 46, n. 7, p. 1159-1170, 1996.

CHUNG WEN, L.; TIAN FUH, S.; SHUANG CHING, C. Monthly changes in the semen characteristics of Duroc boars. Journal of Taiwan Livestock Research, v. 2, p. 8-12, 1996.

CBRA. Colegio Brasileiro de Reprodução Animal. Manual para exame andrológico e avaliação de sêmen animal. $2^{\text {a }}$ Ed. Belo Hte, CBRA, 49 p. 1998.
DESCHAMPS, J.C., BASTOS, R.G., NICOLA, E.S. Avanços da biotecnologia em suínos. Ciência Animal, v. 7, p.79-88, 1997.

DESCHAMPS, J.C.; CORRÊA, M.N.; LUCIA, T. JR. Impacto da inseminação artificial em suínos. Revista brasileira de reprodução animal., v. 22, p. 75-79, 1998.

FLOWERS, W. L. Management of boar for efficient semen production. J. Reprod. Fertil., v. 52, p. 6778, 1997.

FLOWERS WL Selection for boar fertility and semen quality--the way ahead. Soc. Reproduction and Fertility v. 66, p. 67-78, 2009.

FRENEAU, G. E.; PUOLI, J. R.; BORJA, A. L. R. Índice de capacidade andrológica por pontos (ICAP) em touros Nelore: Estudo de estação de acasalamento em Mato Grosso do Sul In. XXXVII Reunião Anual da Sociedade Brasileira de Zootecnia, 37, Viçosa-MG. Anais v. 5, p. 177-181, $2000 . \quad$ Disponível em http://www.sbz.org.br/reuniaoanual/anais/arq_reunia o_anual/sbz2000.rar, acesso em 10 novembro de 2012.

HUANG YH, LO LL, LIU SH, YANG TS. Agerelated changes in semen quality characteristics and expectations of reproductive longevity in Duroc boars. Animal Science Journal v. 81 , n. 4, p. 4327, 2010.

INMET Brasil. http://www.inmet.gov.br/html/ observacoes.php? lnk=Gr\%E1ficos consultado em 25/10/2010.

KUNAVONGKRIT, A., SURIYASOMBOON A., LUNDEHIEM N., HEARD, T., W, EINARSSON, S. Management and sperm production of boars under differing environmental conditions. Theriogenology, v. 63 , p. $657-667,2005$.

KUNAVONGKRIT, A.; PRATEEP, P. Influence of ambient temperature on reproductive efficiency in pigs: (1) boar semen quality. Pig-Journal, v. 35, p.43-47, 1995.

MURASE T, IMAEDA N, YAMADA $\mathrm{H}$, MIYAZAWA K.. Seasonal changes in semen characteristics, composition of seminal plasma and frequency of acrosome reaction induced by calcium and calcium ionophore A23187 in Large White boars. Journal Reproduction Develpment. v. 53, n4,p. 853-65, 2007.

NATIONAL RESEARCH COUNCIL - NRC. Nutrient requirements of swine. 10 ed. Washinton DC. National Academic Press. 189 p., 1998. 
PELTONIEMI, O.A.T.; LOVE, R.J.; HEINONEN, M.; TUOVINEN, V.; SALONIEMI, H. Seasonal and management effects on fertility of the sow: a descriptive study. Animal Reproduction Science, v. 55, p. 47-61, 1999.

RINALDO, D., DIVIDICH, J.L., NOBLET, J. Adverse effects of tropical climate on voluntary feed intake and performance of growing pigs. Livestock Production Science v. 66, p. 223-234, 2000.

ROBERTS, S.J. Veterinary obstetrics and genital diseases (Theriogenology). $3^{\text {rd }}$. Ed. Edwards Brothers Inc. Michigan.981 p. 1986.

ROCA, J; MARTINEZ, S; ORENGO, J; PARRILLA, I; VÁZQUEZ, J.M; MARTÍNEZ, E. Influence of Constant long days on ejaculate parameters of rabbits reared under natural environment conditions of Mediterranean area. Livestock Production Science., v. 94, p. 169-177, 2005.

SAMPAIO, C.A.P, CRISTANI, J, DUBIELA, J.A, BOFF, C.E, OLIVEIRA, M.A. Avaliação do ambiente térmico em instalação para crescimento e terminação de suínos utilizando os índices de conforto térmico nas condições tropicais. Ciência Rural, v. 34, n 3, p. 785-790, 2004.

SAMPAIO, I.B.M. Estatística aplicada à experimentação animal. 2.ed. Belo Horizonte: FEPMVZ 265p. 2002.

SURIYASOMBOON, A.; LUNDEHEIM, N.;
KUNA VONGKRIT, A.; EINARSSON, S. Effect of temperature and humidity on sperm morphology in Duroc boars under different housing systems in Thailand. Journal of Veteterinary Medicine Science, v. 67, n. 8, p. 777-785, 2005.

SURIYASOMBOON A, LUNDEHIEM N, KUNAVONGKRIT A, EINARSSON S. Effect of temperature and humidity on sperm production in Duroc boars under different housing systems in Thailand. Livestock Production Science, v. 89, p. 19-31, 2004.

VALE FILHO, V. R., BERGMAN, J.A.G., ANDRADE, V.J., QUIRINO, C.R., REIS, S,R, MENDOÇA, R.M.A. Caracterização andrológica de touros Nelore, selecionados para primeira estação de monta. Revista Brasileira de Reprodução Animal, v. 21, n. 2, p. 42-45, 1997.

WABERSKI, D., PETRUNKINA, A.M., TÖPFERPETERSEN, E. Can external quality control improve pig AI efficiency?. Theriogenology v.70, p.13461351, 2008.

WETTEMAN, R.P., BAZER, F.W. Influence of environmental temperature on prolificacy in pigs. Journal of Reproduction and Fertility, v. 33, Suppl., p.199-208, 1985.

WETTEMANN, R.P.; DEJARDINS, C. Testicular function in boars exposed to elevated ambient temperature. Biology of Reproduction, v. 20, p. 235-241, 1979.

Protocolado em: 13 jun. 2012. Aceito em: 10 out. 2012. 